\title{
CRESCIMENTO E DESENVOLVIMENTO DE TRÊS ESPÉCIES DE MARACUJAZEIRO NO SUDOESTE GOIANO
}

\author{
Lásara Kamila Ferreira de Souza ${ }^{1}$, Laísse Danielle Pereira², Karminne Dias do Valle ${ }^{3}$, Elionai Feitosa \\ Paiva $^{3}$, Cecília de Castro Bolina ${ }^{4}$, Hildeu Ferreira da Assunção ${ }^{4}$, Edésio Fialho dos Reis ${ }^{4}$, Alejandro \\ Hurtado Salazar ${ }^{5}$, Danielle Fabíola Pereira da Silva ${ }^{4}$
}

\begin{abstract}
RESUMO - A implantação da cultura do maracujazeiro no sudoeste goiano representa uma importante opção de diversificação de cultivo, tendo em vista que o clima da região é altamente favorável. Desta forma, o objetivo do trabalho foi avaliar o crescimento e desenvolvimento da cultivar FB200, Passiflora alata e Passiflora edulis no Sudoeste Goiano. O experimento foi conduzido na Universidade Federal de Goiás - Regional Jataí. Foram plantadas 24 plantas de cada espécie no espaçamento 3x 4m, em sistema de condução de espaldeira com dois fios de arame com irrigação por gotejamento. As amostragens foram realizadas durante o período de crescimento, desenvolvimento e início do florescimento das três espécies em estudo. Foram avaliadas semanalmente até os 70 dias após o transplantio (DAT) as seguintes variáveis: diâmetro do caule (mm), altura da planta $(\mathrm{cm})$, número de gavinhas e botões florais. Os dados obtidos em função dos DAT foram submetidos à análise de variância e de regressão, com F $(\mathrm{p}<0,5)$. As plantas de maracujazeiro da cultivar FB 200 apresentam maior diâmetro de caule e número de botões florais, o que pode indicar que seja a espécie mais produtiva.
\end{abstract}

Palavras-chave: Passiflora alata, Passiflora edulis flavicarpa, taxa de crescimento.

\section{GROWTH AND DEVELOPMENT OF THREE SPECIES OF PASSION FRUIT IN SUDOESTE OF GOIÁS}

\begin{abstract}
The implantation the passionfruit in the southwestern Goias represents an important option for diversification of cropping, bearing in mind that the weather of the region is highly favorable. In this way, the objective of this work was to evaluate the growth and development of the cultivar FB200, Passiflora alata and Passiflora edulis in Southwestern Goias. The experiment was conducted at Federal University of Goias- Regional Jatai. They were planted 24 plants of each species in the spacing $3 \times 4 m$, in the conduction system of trellis with two strands of wire with drip irrigation. The samplings were carried out during the period of growth, development and the beginning of the flowering of the three species under study. They were evaluated weekly until 70 days after transplanting (DAT) the following variables: stem diameter (mm), plant height (cm), number of tendrils and buds. The data obtained in function of the DAT were submitted to analysis of variance and regression, with $F(p<0.5)$. The passion fruit plants of the cultivar FB200 feature increased stem diameter and number of flower buds, which may indicate that the species more productive.
\end{abstract}

Keywords: growth rate, Passiflora alata, Passiflora edulis flavicarpa.

\footnotetext{
${ }^{1}$ Engenheira Florestal - Mestranda do Programa de Pós-graduação em Agronomia (Bolsista da CAPES) - engekah.lk@gmail.com ${ }^{2}$ Engenheira Agrônoma - Mestranda do Programa de Pós-graduação em Agronomia (Bolsista da CAPES) - laissedaniellep@gmail.com ${ }^{3}$ Discente do curso de Agronomia/ Bolsista de Iniciação Científica do CNPq - Universidade Federal de Goiás, Regional Jataí, elionai.fpaiva1@gmail.com, karminnevalle@gmail.com

${ }^{4}$ Engenheiros Agrônomos - Professores - Universidade Federal de Goiás- UFG/Jataí, Goiás -Brasil. ceciliabolina@bol.com.br, hildeu@ufg.br, edesiofr7@gmail.com,daniellefpsilva@gmail.com

${ }^{5}$ Engenheiro Agrônomo - Professor - Universidad de Caldas, Manizales, Colombia, alhuza@gmail.com
} 


\section{INTRODUÇÃO}

A cultura do maracujazeiro apresenta expressão econômica, sendo uma opção de diversificação de cultivo (Costa et al., 2017), em especial para agricultores familiares, é também uma alternativa agrícola que pode propiciar retorno econômico de forma rápida (Meletti et al., 2011). O potencial de produção do maracujá no Brasil e a demanda de mercado, tanto nacional quanto internacional, indicam a importância do cultivo desta frutífera para a economia brasileira (Morgado et al., 2011). O fruto, por possuir muitas características físicoquímicas e efeitos farmacoterápicos, tem tido grande aceitabilidade de mercado, tornando o cultivo cada vez mais promissor (Freitas et al., 2011).

O Brasil se destaca mundialmente como eminente produtor de espécie frutíferas. O Maracujá, por sua vez, vem garantindo grande representatividade e contando com uma produção estimada em 694.539 toneladas e uma produtividade média de $13.66 \mathrm{t}$ ha' ${ }^{1}$ no ano de 2015, com área total colhida de 50.837 ha, sendo que o rendimento médio da produção em Goiás foi de $17.586 \mathrm{~kg} \mathrm{ha}^{-1}$ (Agrianual, 2016).

No estado de Goiás, a área destinada à colheita de maracujá em 2015 foi de 488 ha. Embora seja excelência em produtividade, este tem o seu foco voltado para produção de grãos e especificamente no sudoeste goiano não existe dados de cultivo do Maracujá (IBGE, 2017). Neste sentido, a introdução dessa cultura na região se mostra como uma alternativa altamente viável, tendo em vista que as respostas de crescimento e desenvolvimento das espécies comerciais são satisfatórias.

A avaliação de parâmetros é uma ferramenta útil que permite conhecer o estádio de desenvolvimento da planta e assim inferir sobre sua taxa de crescimento. Por meio da análise quantitativa do crescimento, obtémse o entendimento das relações que envolvam o desenvolvimento nos diferentes processos fisiológico da planta (Peixoto et al., 2011).

A análise quantitativa do crescimento e desenvolvimento é o primeiro passo na avaliação da produção vegetal e requer informações que podem ser obtidas sem a necessidade de equipamentos sofisticados. Assim sendo, o objetivo deste trabalho foi avaliar o crescimento e desenvolvimento de três espécies de maracujazeiro (Cultivar FB 200, Passiflora alata e P. edulis. flavicarpa) no sudoeste de Goiás.

\section{MATERIALE MÉTODOS}

O experimento foi realizado na Universidade Federal de Goiás - Regional Jataí. O Pomar Experimental é caracterizado por latitude $17^{\circ} 53^{\prime}$ sul e longitude $51^{\circ}$ 43' oeste, a 670 m de altitude. O clima da região, segundo a classificação de Köppen, é do tipo Aw, megatérmico, com a estação seca definida de maio a setembro, e a chuvosa, de outubro a abril. O município é localizado na encosta do planalto central.

O plantio foi realizado em casa de vegetação, de forma manual a semeadura, colocando-se 3 sementes de Passiflora edulis flavicarpa (FB 200), Passiflora edulis flavicarpa (Maracujazeiro-azedo) e Passiflora alata (Maracujazeiro-Doce) em cada saco de polietileno de $1 \mathrm{~L}$ a profundidade de $1 \mathrm{~cm}$. Realizou-se o desbaste quando a maioria das plântulas apresentavam $3 \mathrm{~cm}$ de altura, deixando apenas a mais vigorosa. Quando atingiram de 15 a $20 \mathrm{~cm}$, foram transplantadas para sacos de polietileno de $3 \mathrm{~L}$, para melhor desenvolvimento do sistema radicular. As mudas já avançadas, após atingirem tamanho entre 0,80 a $1,50 \mathrm{~m}$, foram transplantadas em setembro de 2016 para o campo de acordo recomendações de Damatto-Junior et al. (2014).

O experimento foi conduzido em blocos causualizados com três tratamentos (espécies) e seis repetições, sendo cada unidade experimental composta por seis plantas. Foram plantadas vinte e quatro plantas de cada espécie no espaçamento 3 x 4 m, em sistema de condução de espaldeira com dois fios de arame com irrigação por gotejamento.

As amostragens foram realizadas durante o período de crescimento, desenvolvimento e início do florescimento das três espécies em estudo, o que ocorreu entre 06 de outubro e 15 de dezembro de 2016.

Foram avaliadas semanalmente até os 70 dias após o transplantio (DAT) as seguintes variáveis: o diâmetro do caule, altura da planta, número gavinha e número de botões florais. O diâmetro do caule foi obtido com paquímetro digital de 0,001 mm de precisão e este foi mensurado na região localizada a $3 \mathrm{~cm}$ acima do colo da planta e os resultados são expressos em milímetros (mm). A altura da planta foi estimada a partir dos 30 DAT, usando fita métrica de $1 \mathrm{~mm}$ de precisão ponderada do colo até o ápice da planta. O número de gavinhas e botões florais foram avaliados por contagem direta. 
Os dados obtidos em função dos dias após o transplantio (DAT) foram submetidos à análise de variância e de regressão, com $\mathrm{F}(\mathrm{p}<0,05)$. Para explicar fisiologicamente o comportamento das plantas utilizaramse modelos de regressões, sendo a escolha dos modelos baseada no coeficiente de determinação e no potencial, para explicar o fenômeno biológico. Os dados foram analisados no software estatístico SAS (Statistical Analysis System, 2002).

\section{RESULTADOS E DISCUSSÃO}

No $51^{\circ}$-DAT o diâmetro do caule foi de $13,81 \mathrm{~mm}$; 13,15 mm e 7,15 mm para FB200, Maracujá-azedo e Maracujá-doce, respectivamente (Figura 1).

Em estudo com enxertia em Passiflora sp., Cavicholi et al. (2011) constataram que um indicativo de vigor da planta é o diâmetro. Devido a isso, obtémse maiores rendimentos em produção quando há maior vigor vegetativo inicial, o que contribui para o entendimento de que quanto maior o diâmetro do caule, maiores serão as possibilidades das plantas apresentarem alta produtividade (Santos et al., 2016).

Aos $60^{\circ}$ DAT o diâmetro do caule foi de $15,31 \mathrm{~mm}$; 14,38mm e 7,11mm, para FB200, Maracujá-azedo e Maracujá-doce. Aos 72 dias, obtiveram-se os valores de 17,00; 16,14 e 7,04 mm para FB 200, Maracujá-azedo e Maracujá-doce, respectivamente. O maracujazeiro-

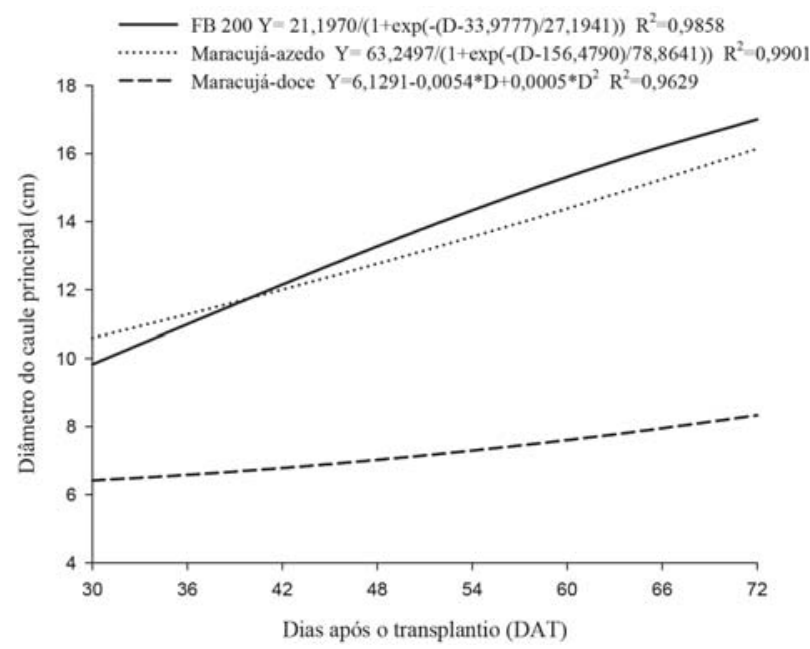

Figura 1 - Dados ajustados para diâmetro do caule principal de três espécies de maracujazeiro cultivados no Sudoeste Goiano, Jataí, 2017. doce apresentou menor vigor e menor evolução dentre as espécies avaliadas. Enquanto que a cultivar comercial FB 200 alcançou os maiores valores de diâmetro do caule durante todo o período de crescimento da planta.

No $51^{\circ}$ DAT observou-se altura do caule principal de 2,45 m; 2,39 m e 2,59 m para FB200, Maracujá-azedo e Maracujá-doce, respectivamente (Figura 2). Já aos $60^{\circ}$ (DAT) verificou-se a altura de caule principal de 3,00; 2,93 e 2,85 m para Maracujá-doce, FB 200 e Maracujá-azedo, respectivamente.

Aos $72^{\circ}$ DAT os resultados foram de 3,68; 3,53 e 3,47m para FB 200, Maracujá-azedo e Maracujá-doce. Esses resultados demonstram que durante todo o período de avaliação de crescimento das plantas, a cultivar FB 200 se destacou para a característica altura da planta.

Analisando o desenvolvimento, florescimento e a morfoanatômia do maracujazeiro-amarelo enxertado em espécies silvestres do gênero passiflora, Salazar et al. (2016) constataram que aos 58 (DAT), as plantas provenientes de sementes apresentaram superioridade na altura em relação as enxertadas. Entretanto, o maracujazeiro P. edulis/P. edulis, em torno dos 120 (DAT) superou a altura de $P$. edulis provenientes de sementes, o que indica que apenas no período imediato após a enxertia (30 DAT).

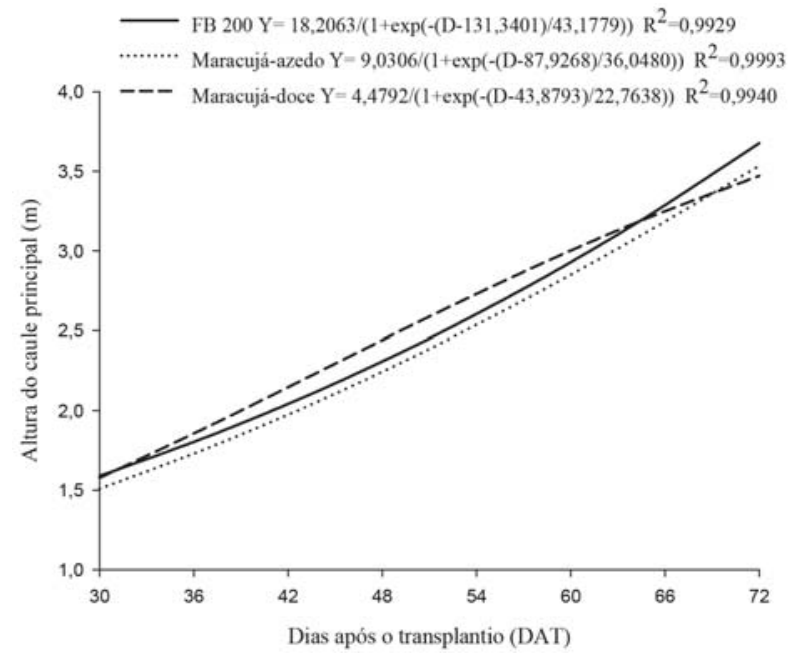

Figura 2 - Dados ajustados para altura do caule principal de três espécies de maracujazeiro, cultivados no Sudoeste Goiano, Jataí, 2017. 
Aos $51^{\circ}$ DAT observou-se número de gavinhas 16,36; 16,20 e 22,33 gavinhas para FB200, Maracujáazedo e Maracujá-doce, respectivamente (Figura 3). César et al. (2015) ressaltam que quando é emitida a primeira gavinha e a primeira folha trilobada, ocorre o marco da transição entre a fase juvenil e a adulta, em seu estudo com Passiflora edulis sims f. flavicarpa degene. Assim, para as três espécies em estudo, o marco entre a transição entre a fase juvenil e a adulta no presente trabalho foi marcado aos $30 \mathrm{DAT}$, o que demonstra a precocidade destas espécies quando conduzidas no Sudoeste Goiano.

As gavinhas possuem importante função na planta, pois são responsáveis pela fixação e sustentação. Entretanto, em excesso estas podem ser prejudiciais ao bom desenvolvimento da planta, ocorrendo entrelaçamento dos ramos produtivos e também de hastes. Todavia, estas podem ser indicativo do momento de plantio em campo. É importante salientar que na fase reprodutiva é seguindo o padrão que a cada um nó, a planta apresente uma gavinha e um botão floral.

Aos $91^{\circ}$ DAT observou-se número de botões florais de 37,57; 18,77 e 0,63 botões florais para FB200, Maracujá-azedo e Maracujá-doce, respectivamente (Figura 4).

Aos $98^{\circ}$ DAT as espécies FB 200, Maracujá-azedo e Maracujá-doce apresentaram respectivamente 71,91;

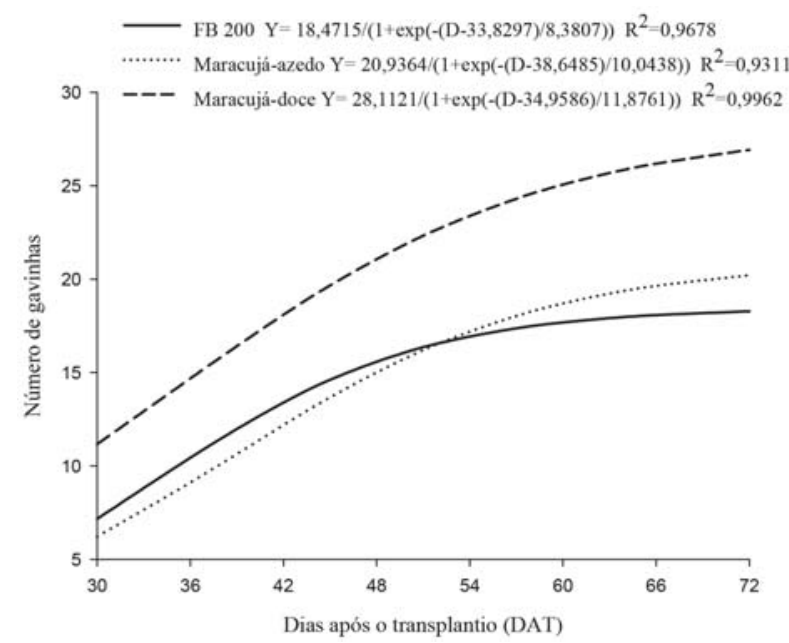

Figura 3 - Dados ajustados para número de gavinhas de três espécies de maracujazeiro, cultivados no Sudoeste Goiano, Jataí, 2017.
39,67 e 5,35. Aos $105^{\circ}$ DAT para quantidade de botões florais verificou-se o total FB 200, Maracujá-azedo e Maracujá-doce, respectivamente os valores de 155,24; 78,23 e 10,39.

Para a cultura do maracujá é desejável que se tenha fotoperíodo superior a 11 horas. Durante a condução do experimento, tal condição foi observada, e com isso houve a diferenciação dos botões florais. Em trabalho realizado por Salazar et al. (2016) observaram o comportamento da planta ao acúmulo de unidades térmicas até o florescimento. Com temperaturas médias diárias oscilando além da faixa de variação considerada ideal para a planta, que se situa entre $24 \mathrm{e} 28^{\circ} \mathrm{C}$, correspondendo a uma época de fotoperíodo decrescente, entre os meses de abril a agosto. Com isso, foi contatado que a menor exigência em unidades térmicas confirmou a precocidade das plantas.

César et al. (2015) avaliando o efeito da aplicação foliar de $\mathrm{Ga}_{3}$ no crescimento e desenvolvimento de Passiflora edulis sims f. flavicarpa degener, observaram 21 botões florais na presença de $\mathrm{Ga}_{3}$ e na ausência 13 botões florais, constando que o uso das giberelinas induz o processo de florescimento do maracujazeiro.

O desenvolvimento da parte aérea das plantas ou com maior crescimento desse segmento são desejáveis, porém isto, não deve refletir em custos elevados na produção, devendo apenas contribuir para

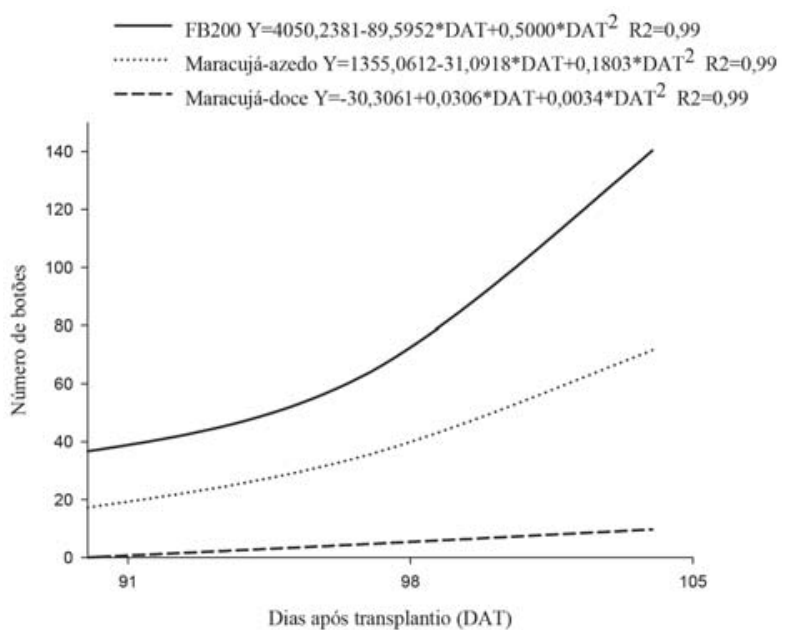

Figura 4 - Dados ajustados para número de botões de três espécies de maracujazeiro, cultivados no Sudoeste Goiano, Jataí, 2017. 
maior produtividade sem promover o aumento do período de juvenilidade (Morgado et al., 2015).

Compreender o crescimento e o desenvolvimento do maracujazeiro possibilita a implantação de estratégias de manejo para o alto rendimento. Para todas as características avaliadas observou-se maior destaque para a cultivar FB 200 para a região do sudoeste goiano.

\section{CONCLUSÕES}

A transição entre a fase juvenil e a adulta marcada aos 30 DAT para as três espécies em estudo, o que demonstra a precocidade destas espécies quando conduzidas no Sudoeste Goiano.

As plantas do maracujazeiro FB200 apresentam maior diâmetro do caule e maior número de botões florais.

\section{AGRADECIMENTOS}

Ao CNPq (Conselho Nacional de Desenvolvimento Científico e Tecnológico), CAPES (Coordenação de Aperfeiçoamento de Pessoal de Nível Superior) e FAPEG (Fundação de Amparo à Pesquisa do Estado de Goiás), pelo apoio financeiro.

\section{LITERATURA CITADA}

AgRianual. Anuário da agricultura brasileira. São Paulo: Fnp Consultoria \& Agroinformativo, 2016. 456p.

CAVICHIOLI, J.C.; CORRÊA, L.D.S.; GARCIA, M.J.D.M. et al. Desenvolvimento, produtividade e sobrevivência de maracujazeiro-amarelo enxertado e cultivado em área com histórico de morte prematura de plantas. Revista Brasileira de Fruticultura, p.567-574, 2011.

CEZAR, A.M.A.; SORGATO, J.C.; ROSA, D.B.C.J. et al. GA3 LEAF Application on Growth and Development of Passiflora edulis Sims $f$. flavicarpa Degener. Revista Brasileira de Fruticultura, v.37, n.4, p.902-912, 2015.

COSTA, R.C.; ISHIDA, A.K.N.; MIRANDA, V.S. et al. Extratos vegetais, formulações a base de extrato vegetal e produtos químicos no controle da mancha bacteriana do maracujazeiro. Revista Brasileira de Agropecuária Sustentável (RBAS), v.7, p.26-33, 2017.
DAMATTO-JUNIOR, E.R.; FUZITANI, E.J.; NOMURA, E.S. Produção de maracujá com uso de mudas avançadas no Vale do Ribeira.

Pesquisa \& Tecnologia, v.11, n.1, 2014.

FREITAS, J.P.X.; OLIVEIRA, E.J.; CRUZ NETO, A.J. et al. Avaliação de recursos genéticos de maracujazeiro-amarelo.

Pesquisa Agropecuária Brasileira, Brasília, v.46, n.9, p.1013-1020, 2011.

IBGE. 2017. Banco de dados agregados do Instituto Brasileiro de Geografia e Estatística. Produção Maracujá 2015. Disponível em: http://www.sidra.ibge.gov.br. Acesso em: 18 de agosto de 2017.

MELETTI, L.M.M. Avanços na cultura do maracujá no Brasil. Revista Brasileira de Fruticultura, v.33, n.1, p.83-91,2011.

MORGADO, M.A.D.O.; BRUCKNER, C.H.; ROSADO, L.D.S. et al. Desenvolvimento de mudas de maracujazeiro-azedo enxertadas em espécies silvestres de Passiflora. Revista Brasileira de Fruticultura, v.37, p.471479, 2015.

MORGADO, M.A.D.; BRUCKNER, C.H.; FIALHO, G.S. et al. Non-destructive estimation of chlorophyll content in yellow passion fruit leaves. Revista Brasileira de Agropecuária Sustentável (RBAS), v.1, p.71-75, 2011.

PEIXOTO, C.P; CRUZ, T.V; PINTO, M.F.S. Análise quantitativa do crescimento de plantas: Conceitos e Prática. Enciclopédia Biosfera, Centro Científico Conhecer Goiânia, v.7, n.13, 2011.

SALAZAR, A.H.; SILVA, D.F.P.; PICOLI, E.T. et al. Desenvolvimento, florescimento e análise morfoanatômica do maracujazeiroamarelo enxertado em espécies silvestres do gênero passiflora. Agrária, Recife, v.11, n.4, p.323-329, 2016. 
SANTOS, C.H.B., CRUZ NETO, A.J.D., SOARES, T.L. et al. Rootstocks and tying materials for hipocotyledonar grafting of yellow passion fruit. Ciência Rural, v.46, n.1, p.30-35, 2016.

STATISTICAL ANALYSIS SYSTEM. SAS

Institute. Cary, N.C, EEUU. Version 9.0. 2002.
VENDRUSCOLO, E.P.; MARTINS, A.P.B.; SELEGUINI, A. Doses e parcelamento de niacina no desenvolvimento inicial de meloeiro Cantaloupe. Revista agro@mbiente on-line, v.11, n.3, p.209-214, 2017.

Recebido para publicação em 14/10/2017 e aprovado em 28/03/2018. 